\title{
DESAIN PENGENDALI PID - GAIN SCHEDULLING UNTUK PENGENDALIAN POSISI PADA SISTEM MAGNETIC LEVITATION BALL
}

\author{
Dian Mursyitah $^{1}$, Ahmad Faizal ${ }^{2}$, Rahmat Andi Kurniawan ${ }^{3}$ \\ Program Studi Teknik Elektro, Fakultas Sains dan Teknologi, UIN SUSKA RIAU ${ }^{1,2,3}$ \\ Jl. HR. Soebrantas Km. 155 Pekanbaru - Riau \\ e-mail: dmursyitah@uin-suska.ac.id ${ }^{1}$
}

\begin{abstract}
This study propose a design of PID controller with gain schedulling optimization to controlling position for Magnetic Levitation Ball (Maglev) system. Design of PID controller with gain schedulling optimization are used to control three steel ball positions. Gain scheduling is designed to schedule each PID parameter to control the three predefined steel ball positions. Based on simulation and analysis result, gain scheduling is able to optimize PID controlling performance for controlling three steel ball positions. Proven by minimum setpoint attainment time are $\tau=0.393 s, \tau=0.408 s, \tau=0.413$ s for each position.
\end{abstract}

Keywords: Gain Schedulling, PID, Position

\section{INTISARI}

Penelitian ini mengajukan desain pengendali PID dengan optimasi Gain Schedulling untuk mengendalikan posisi untuk sistem Magnetic Levitation Ball (Maglev). Desain pengendali PID dengan optimasi gain schedulling digunakan untuk mengendalikan tiga posisi bola baja. Gain Schedulling dirancang untuk menjadwalkan masing-masing parameter PID untuk mengendalikan tiga posisi bola baja yang telah ditentukan. Berdasarkan hasil simulasi dan analisis, Gain Schedulling mampu mengoptimalkan kinerja pengendalian PID untuk mengendalikan tiga posisi bola baja. Terbukti dengan waktu pencapaian setpoint yang minimum, dengan nilai konstanta waktu secara berurutan adalah $\tau=0.393 \mathrm{~s}, \tau=0.408 \mathrm{~s}, \tau=0.413$

Kata kunci: Gain Schedulling, PID, Posisi

\section{PENDAHULUAN}

Magnetic levitation Ball bukanlah istilah baru di industri, dan telah diaplikasikan di berbagai bidang. Prinsip kerjanya adalah melayangkan objek menggunakan daya magnet. Magnetic levitaion inilah yang sekarang disadur untuk diaplikasikan pada sistem kereta super cepat yang disebut magnetic levitation train. Pengendalian posisi menjadi sangat penting agar tidak terjadi gesekan antara objek pelayangan dan permukaan. Objek dalam hal ini bola baja harus dikendalikan sesuai posisi yang telah ditentukan walaupun terdapat berbagai macam gangguan.[1][2][3].

$$
\text { Beberapa penelitian telah }
$$
dilakukan untuk mengendalika posisi pada sistem maglev, yaitu pengendalian posisi menggunakan pengendali PID. Performansi yang dihasilkan baik namun terdapat kekurangan ketika posisi mengalami perubahan, akibatnya masingmasing parameter PID harus diatur ulang [4][5]. Permasalah tersebut kemudian diselesaikan dengan menggunakan kendali cerdas Fuzzy Logic Controller yang dikombinasikan dengan gain 
schedulling. Kelemahan yang muncul adalah komplesitas yang tinggi dalam penurunan model matematis dan perancangan rule pada fuzzy. Hal ini disebabkan karena terdapat tiga posisi bola baja yang berbeda, yang harus dijadwalkan oleh fuzzy dan gain schedulling[6]

Pada penelitian ini dipilih pengendali PID. Walaupun pengendali PID merupakan pengendali konvensional, berdasarkan survey yang dilakukan honeywell pengendali PID masih banyak digunakan oleh 97\% dunia industri masih menggunakan pengendali PID pada proses produksinya. Masing-masing kendali pada pengendali PID memiliki efek tersediri bagi sistem, yaitu proporsional yang berfungsi untuk memperbaik rise time, integral yang berfungsi untuk menghilangkan error steady state, dan derivatif yang berfungsi untuk memperbaiki overshoot. Namun, PID juga memiliki kekurangan yaitu dalam mendapatkan parameter yang tepat untuk masing-masing komponen P, I dan $D[7]$. Kemudian, pengendali PID tidak cocok jika diterapkan pada sistem non linier, karena umumnya sistem non linier memiliki ketidakpastian parameter. PID juga tidak mampu mengatasi perubahan parameter secara tiba-tiba dengan waktu yang cepat. Selain itu, pengendali PID juga belum cukup mampu mengatasi perubahan kondisi sistem. Akibatnya pencarian komponen $\mathrm{P}$, I dan $\mathrm{D}$ harus dilakukan ulang sehingga tidak efisien dari segi waktu. Oleh sebab itu, untuk mendapatkan hasil optimal pengendali PID dapat dikombinasikan dengan pengendali lain[7][8]

\section{METODE PENELITIAN}

Metode Penelitian dimulai dengan studi literatur, validasi model matematis sistem maglev ball, kemudian dilanjutkan dengan perancangan pengendali PID dan
Gain Schedulling, langkah selanjutnya adalah mensimulasikan model matematis sistem bersama hasil rancangan pengendali untuk masing-masing posisi, dan dianalisa hasil dan pembahasan.

\section{Pengujian model matematis sistem maglev ball[1][2]}

Gambar 1 memperlihatkan model dan struktur pelayangan magnet pada bola baja (magnetic levitation ball). Adapun komponen dan struktur Magnetic Levitation Ball ini terdiri dari:

1. Digital to Analog Converter (DAC) yang berfungsi sebagai pengubah sinyal digital menjadi sinyal analog.

2. Power amplifier berfungsi sebagai sumber arus yang konstan.

3. Solenoida berfungsi sebagai magnet untuk melawan gaya gravitasi. Dan bola baja yang berfungsi sebagai benda yang akan dilayangkan.

4. Sensor Posisi berfungsi untuk menentukan jarak benda dengan elektromagnet.

5. Analog to Digital Converter (ADC) berfungsi untuk mengubah sinyal analog menjadi sinyal digital

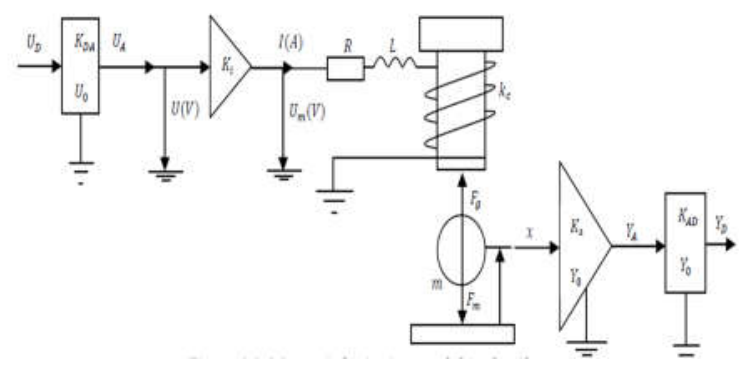

Gambar 1. Sistem maglev ball[1] [2]

Model Matematis Sistem Magnetic Levitation Ball dalam skala laboratorium diperoleh dengan cara menurunkan 
persamaan matematis masing-masing komponen sistem. Pada penelitian ini model matematis merujuk penelitian sebelumnya, sehingga yang dilakukan hanya melakukan validasi. Jika hasil keluaran yang dihasilkan sama dengan rujukan penelitian maka model matematis dianggap valid, sehingga dapat dilakukan perancangan pengendali dengan metode yang berbeda. Berdasarkan hasil penurunan model matematis diperoleh bentuk state space equation sebagai berikut :

$$
\begin{gathered}
\left.\left[\begin{array}{c}
\dot{\mathrm{x}}_{1} \\
\dot{\mathrm{x}}_{2}
\end{array}\right]=\left[\begin{array}{cc}
0 & 1 \\
\frac{-2 k_{F} u_{s s}^{2}}{n\left(x_{\mathrm{Iss}}-x_{\mathrm{LD}}\right)^{3}} & \frac{-k_{f v}}{m}
\end{array}\right] \begin{array}{l}
x_{1} \\
x_{2}
\end{array}\right]+\left[\begin{array}{c}
0 \\
\frac{2 k_{F} K_{D} u_{s s}}{n\left(x_{1 s s}-x_{L 0}\right)^{2}}
\end{array}\right] U_{D} \\
y=\left[\begin{array}{ll}
k_{x}^{*} K_{A D} & 0
\end{array}\right]\left[\begin{array}{l}
x_{1} \\
x_{2}
\end{array}\right]
\end{gathered}
$$

Dengan mensubtitusikan nilai

$U_{s s}=\sqrt{\frac{m g}{k_{F}}}\left(x_{1 s s}-x_{L 0}\right)$ model state space menjadi :

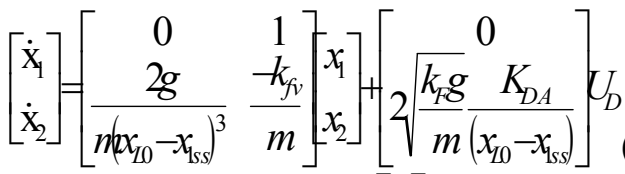

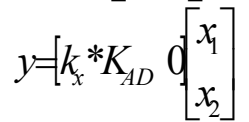

Tabel 1 Nilai-nilai parameter dari magnetic ball levitation [1][2]

\begin{tabular}{|l|l|l|}
\hline Parameter & Symbol & Nilai \\
\hline Diameter bola & $D_{k}$ & $12.7 \mathrm{e}-3 \mathrm{~m}$ \\
\hline Massa Bola & $M$ & $0.0084 \mathrm{~kg}$ \\
\hline Jarak dari dasar & $\mathrm{T}_{\mathrm{d}}$ & $0.0019 \mathrm{~m}$ \\
\hline $\begin{array}{l}\text { Batas jarak }= \\
0.0019-D_{k}\end{array}$ & $\mathrm{~L}$ & $0.0063 \mathrm{~m}$ \\
\hline $\begin{array}{l}\text { Viscose } \\
\text { friction }\end{array}$ & $k_{f v}$ & $0.02 \mathrm{~N} . \mathrm{s} / \mathrm{m}$ \\
\hline $\begin{array}{l}\text { Konstanta } \\
\text { Gravitasi }\end{array}$ & $G$ & $9.81 \mathrm{~m} / \mathrm{s}^{2}$ \\
\hline Aggregated & $k_{F}$ & $0.606 \times 10^{-}$ \\
\hline
\end{tabular}

\begin{tabular}{|l|l|l|}
\hline coil constant & & ${ }^{6} \mathrm{~N} / \mathrm{V}$ \\
\hline $\begin{array}{l}\text { Penguatan } \\
\text { Konverter }\end{array}$ & $K_{D A}$ & 10 \\
\hline Coil bias & $x_{L 0}$ & $8.26 \times 10^{-3} \mathrm{~m}$ \\
\hline $\begin{array}{l}\text { KOnstanta } \\
\text { sensor posisi }\end{array}$ & $k_{x}$ & 797.4603 \\
\hline $\begin{array}{l}\text { Analog to } \\
\text { digital } \\
\text { converter gain }\end{array}$ & $K_{A D}$ & 0.2 \\
\hline $\begin{array}{l}\text { Maximum DA } \\
\text { converter } \\
\text { output voltage }\end{array}$ & $\mathrm{U}_{\text {Dam }}$ & $5 \mathrm{~V}$ \\
\hline Coil resistance & $\mathrm{Rc}$ & $3.5 \Omega$ \\
\hline Coil inductance & $\mathrm{Lc}$ & $30 \times 10^{-3} \mathrm{H}$ \\
\hline $\begin{array}{l}\text { Current sensor } \\
\text { gain }\end{array}$ & Ks & 13.33 \\
\hline $\begin{array}{l}\text { Power } \\
\text { amplifier gain }\end{array}$ & Kam & 100 \\
\hline Setah mensubitusikan & \multicolumn{1}{|c|}{ nilai-nilai }
\end{tabular}

Setelah mensubtitusikan nilai-nilai parameter dari magnetic ball levitation dari Tabel 1, state space (2) menjadi :

$$
\begin{gathered}
\left.\left[\begin{array}{l}
\dot{\mathrm{x}}_{1} \\
\dot{\mathrm{x}}_{2}
\end{array}\right]=\left[\begin{array}{cc}
0 & 1 \\
\frac{1962}{\left(0.00826 x_{1 s s}\right)} & -2381
\end{array}\right] \begin{array}{l}
x_{1} \\
x_{2}
\end{array}\right]+\left[\begin{array}{c}
0 \\
0.53206 \\
\left(0.00826 x_{1 s s}\right)
\end{array}\right] U_{D} \\
y=[159992060]\left[\begin{array}{l}
x_{1} \\
x_{2}
\end{array}\right]
\end{gathered}
$$

Berdasarkan persamaan tersebut dilakukan modifikasi model dengan menurunkan persamaan matematis sistem untuk tiga posisi berbeda sebagai berikut

\section{Posisi 0.01m}

$[0.01-$ ball diameter $]=[0.01-$

$0.005]$ so $x_{1 s s}=\frac{[0.005]}{2}=0.0025[4]$

Subsitusikan $x_{1 s s}$ pada persamaan (3), sehingga membentuk persamaan (4) : 


$$
\begin{gathered}
{\left[\begin{array}{l}
\dot{\mathrm{x}}_{1} \\
\dot{\mathrm{x}}_{2}
\end{array}\right]=\left[\begin{array}{cc}
0 & 1 \\
340625 & -2.381
\end{array}\right]\left[\begin{array}{l}
x_{1} \\
x_{2}
\end{array}\right]+\left[\begin{array}{c}
0 \\
92.37
\end{array}\right] U_{D}} \\
y=\left[\begin{array}{ll}
159.49206 & 0
\end{array}\right]\left[\begin{array}{l}
x_{1} \\
x_{2}
\end{array}\right]
\end{gathered}
$$

Fungsi transfer didefinisikan : $\mathrm{G}(\mathrm{s})=$ $\mathrm{C}(\mathrm{SI}-\mathrm{A})^{-1} \mathrm{~B}$, sehingga

$$
\begin{gathered}
G(s)=[1599206)\left(\left[\begin{array}{ll}
s & 0 \\
0 & s
\end{array}\right]-\left[\begin{array}{cc}
0 & 1 \\
340 \varnothing 5 & -238
\end{array}\right]\right)^{-1}\left[\begin{array}{c}
0 \\
9237
\end{array}\right] \\
G(s)=\frac{14732.281}{s^{2}+2.381 s-3406.25}=\frac{N(s)}{D(s)}
\end{gathered}
$$

Close loop dari fungsi trasnfer tanpa kendali menjadi :

$$
T F=\frac{G(s)}{1+G(s)}=\frac{\frac{N(s)}{D(s)}}{1+\frac{N(s)}{D(s)}}=\frac{N(s)}{N(s)+D(s)}
$$

Kemudian fungsi transfer untuk posisi $0.01 \mathrm{~m}$ adalah sebagai berikut :

$$
T F=\frac{14732.281}{s^{2}+2.381 s+10966.031}
$$

\section{Posisi 0.0125 m}

$[0.0125-$ ball diameter $]=$ $[0.0125-0.005]$ sehingga $x_{1 s s}=$ $\frac{[0.0075]}{2}=0.00375 \mathrm{~m}$

$$
G(s)=\frac{18815.27}{s^{2}+2.381 s-4350.33}=\frac{N(s)}{D(s)}
$$

Kemudian fungsi transfer untuk posisi $0.012 \mathrm{~m}$ adalah sebagai berikut :

$$
T F=\frac{18815.27}{s^{2}+2.381 s+14464.94}
$$

\section{Posisi 0.015 m}

$[0.015-$ ball diameter $]=$ $[0.015-0.005]$ sehingga $x_{1 s s}=\frac{[0.01]}{2}=$ $0.005 m$

$$
G(s)=\frac{26030.69}{s^{2}+2.381 s-6018.40}=\frac{N(s)}{D(s)}
$$

Kemudian fungsi transfer untuk posisi $0.015 \mathrm{~m}$ adalah sebagai berikut

$$
T F=\frac{26030.69}{s^{2}+2.381 s+20012.29}
$$

\section{Perancangan Pengendali PID-Gain Schedulling[7][8]}

Perancangan pengendodj PID-Gain Schedulling dimulai denganmendapatkan parameter PID yang sesuai untuk masingmasing posisi. Parameter PID diperoleh dengan metode heuristic. Langkah yang perlu dilakukan adalah mendapatkan Scheduller Variable (SV), untuk itu perlu dilakukan pengujian Bump Test dengan memberikan input pada pengendali (CO) seperti pada Tabel 2 .

Tabel 2. Variabel Penjadwalan [7][8]

\begin{tabular}{|l|l|l|l|}
\hline & Kp & Ti & TD \\
\hline Kondisi 1: & Kp & Ti & TD1 \\
$0.01 \mathrm{~m}<$ SV $<0.0125 \mathrm{~m}$ & 1 & 1 & \\
\hline Kondisi 2 : & Kp & Ti & TD2 \\
$0.0125 \mathrm{~m}<$ SV $<0.015 \mathrm{~m}$ & 2 & 2 & \\
\hline Kondisi 3: & Kp & Ti & TD3 \\
SV $>0.015 \mathrm{~m}$ & 3 & 3 & \\
\hline
\end{tabular}


untuk mendapatkan nilai SV terlebih dahulu dilakukan pengujian bump test dengan memberi respon tangga control output (CO) pada keadaan tetap, kemudian diperoleh fungsi transfer sebagai berikut :

$G_{p}(s)=\frac{y_{(S)}}{u_{(s)}}=\frac{K_{p}{ }^{-\theta p s}}{T_{p} s+1}$

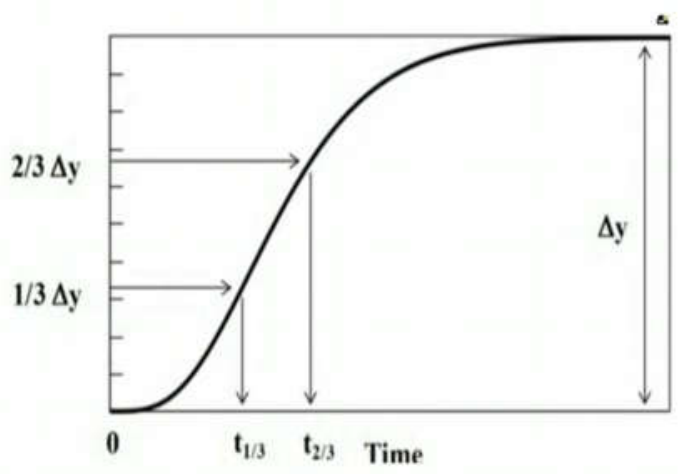

Gambar 2. Pengujian Bump Test [7][8]

Dimana :

$\tau_{p}=\frac{1}{0.7}\left(t_{2 / 3}-t_{1 / 3}\right)$

$\theta_{p=} t_{1 / 3}+0.4 \tau_{p}$

$K_{p}=\frac{\Delta y}{\Delta u}$

Dengan :

$K_{p} \quad$ : Penguatan statis

$\theta_{p} \quad:$ Waktu tunda

$\tau_{p} \quad:$ Konstanta waktu

$t_{1 / 3}$ : Nilai $P V$ ketika $1 / 3$ dari steady state

$t_{2 / 3}$ : Nilai $P V$ ketika $2 / 3$ dari steady state

$\Delta y \quad$ : Perubahan steady state pada keluaran proses

$\Delta u \quad$ : Perubahan step pada masukan
Hasil diperoleh dengan melihat hasil keluran sperti yang ditunjukkan pada Gambar 3.

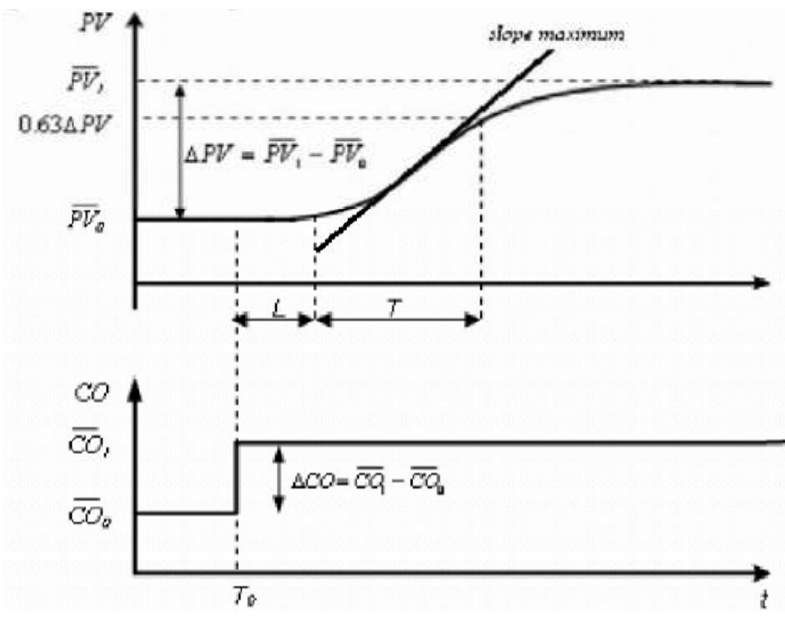

Gambar 3. Hasil pengujian Bump Test [7][8]

Kemudian mendapatkan nilai $\mathrm{K}$ dengan menyelesaikan persamaan (16)

$$
K=\frac{\Delta P V}{\Delta C O}=\frac{P V_{1}-P V_{0}}{C O_{1}-C O_{0}}
$$

Setelah mendapatkan parameter gain scheduling, maka untuk mendapatkan parameter PID digunakan metode Zielger-Nichols 1 yang diperlihatkan pada Tabel 3

Tabel 3. Rumus parameter PID dengan metode Ziegler-Nichols metode ke1.[7][8]

\begin{tabular}{|l|c|c|c|}
\hline Pengendali & $\mathrm{Kp}$ & $\mathrm{Ti}$ & $\mathrm{Td}$ \\
\hline $\mathrm{P}$ & $\frac{T}{K \cdot L}$ & - & - \\
\hline PI & $0,9 \frac{T}{K \cdot L}$ & $3,33 L$ & \\
\hline PID & $1,2 \frac{T}{K \cdot L}$ & $2 L$ & $0,5 L$ \\
\hline
\end{tabular}

Sehingga diperoleh parameter gain schedulling yang sebagai berikut : 
Tabel 4. Parameter PID untuk tiga kondisi

\begin{tabular}{|l|c|c|c|}
\hline & $\mathrm{Kp}$ & $\mathrm{Ti}$ & $\mathrm{TD}$ \\
\hline $\begin{array}{l}\text { kondisi 1: } \\
0.01 \mathrm{~m}<\mathrm{SV}<0.0125 \\
\mathrm{~m}\end{array}$ & 1.04 & 1.4 & 0.35 \\
\hline $\begin{array}{l}\text { kondisi 2: } \\
0.0125 \mathrm{~m}<\mathrm{SV}<0.01\end{array}$ & $\begin{array}{c}1.02 \\
7\end{array}$ & $\begin{array}{c}1.39 \\
4\end{array}$ & $\begin{array}{c}0.34 \\
8\end{array}$ \\
\hline $\begin{array}{l}\text { kondisi 3: } \\
\mathrm{SV}>0.015 \mathrm{~m}\end{array}$ & 1.01 & 1.5 & $\begin{array}{l}0.37 \\
5\end{array}$ \\
\hline
\end{tabular}

\section{ANALISA DAN HASIL}

\section{Hasil Simulasi Sistem Maglev Ball Tanpa Pengendali}

Berdasarkan persamaan (3) dibentuk fungsi transfer sistem magnetic levitation ball. Dan hasil simulasi ditunjukkan pada Gambar 4.

$$
T F=\frac{\text { Position }}{\text { Voltage }}=\frac{x}{V}=\frac{14732.281}{s^{2}+2.381 s+10966.031}
$$

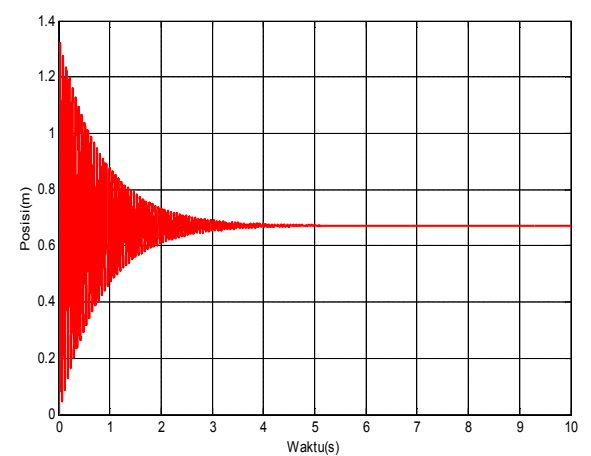

Gambar 4. Hasil Respon Keluaran Sistem Maglev Tanpa Pengendali

Berdasarkan Gambar 4, sistem diberikan masukan sebesar $0.5 \mathrm{~V}$ hasil menunjukkan bahwa sistem mengalami osilasi yang besar di awal, dan error yang cukup besar juga terjadi, hal ini menunjukkan sistem maglev sangat tidak stabil.

\section{Hasil Simulasi Sistem Maglev Ball dengan Pengendali PID-Gain Schedulling}

Berdasarkan model matematis sistem dan desain kendali untuk tiga posisi menghasilkan respon sebagai berikut :

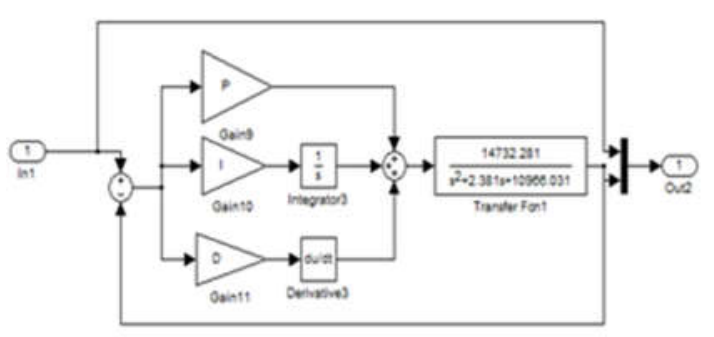

(a)

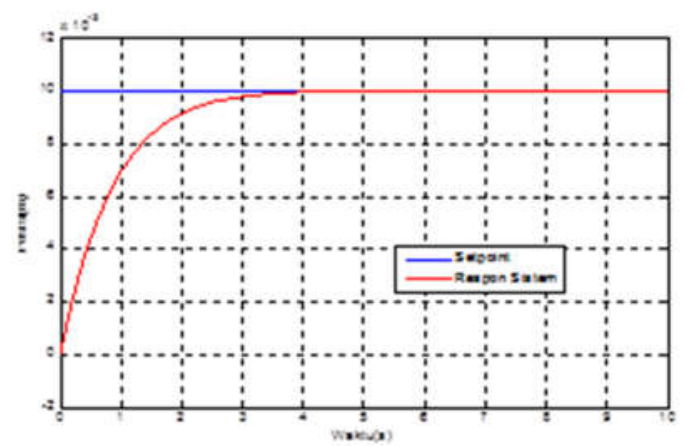

(b)

Gambar 5. (a) Blok diagram program simulasi untuk posisi $0.01 \mathrm{~m}$ (b) Hasil Respon untuk posisi $0.01 \mathrm{~m}$ menggunaan PID-Gain Schedulling

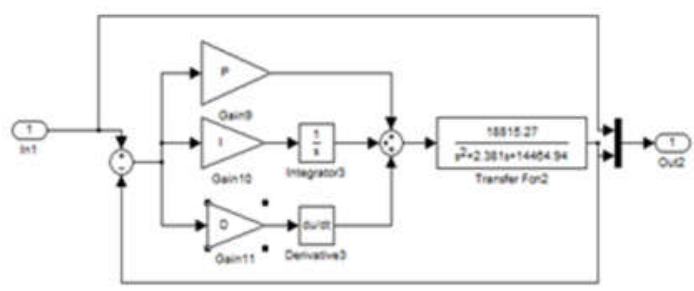

(a) 


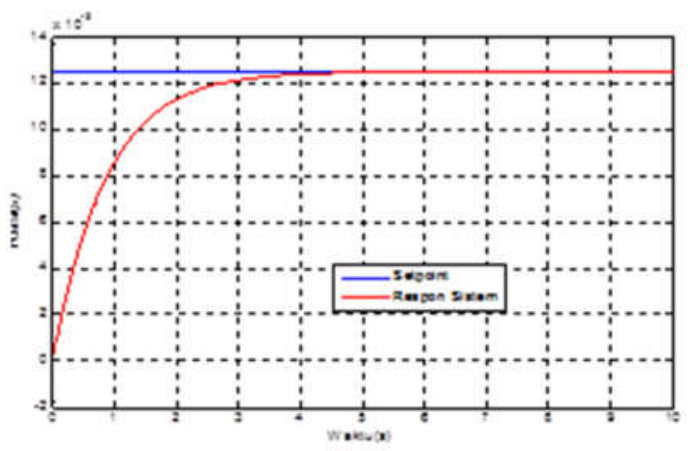

(b)

Gambar 6. (a) Blok diagram program simulasi untuk posisi $0.0125 \mathrm{~m}$ (b) Hasil Respon untuk posisi $0.0125 \mathrm{~m}$ menggunaan PID-Gain Schedulling

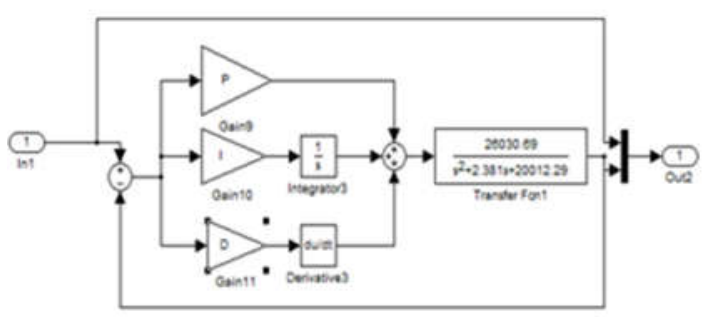

(a)

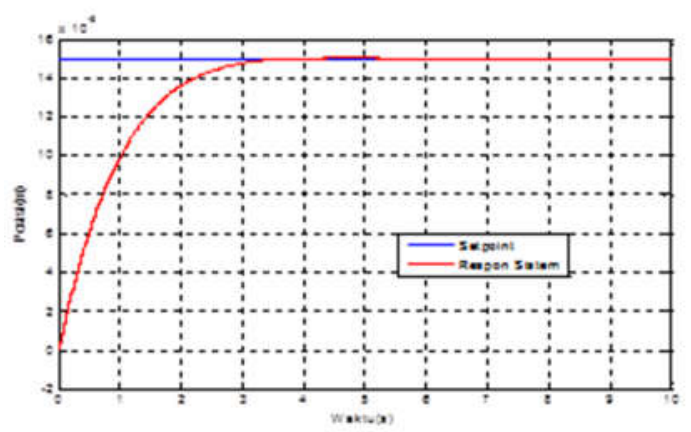

(b)

Gambar 7. (a) Blok diagram program simulasi untuk posisi $0.015 \mathrm{~m}$ (b) Hasil Respon untuk posisi $0.015 \mathrm{~m}$ menggunaan PID-Gain Schedulling
Tabel 5. Analisa Respon Sistem Maglev Ball Menggunakan Pengendali PID-Gain Schedulling

\begin{tabular}{|c|c|c|c|}
\hline $\begin{array}{c}\text { Analisa } \\
\text { respon }\end{array}$ & $\begin{array}{c}\text { Posisi } \\
0.01 \mathrm{~m}\end{array}$ & $\begin{array}{c}\text { Posisi } \\
0.0125 \mathrm{~m}\end{array}$ & $\begin{array}{c}\text { Posisi } \\
0.015 \mathrm{~m}\end{array}$ \\
\hline$T$ & $0.393 \mathrm{~s}$ & $0.408 \mathrm{~s}$ & $0.413 \mathrm{~s}$ \\
\hline $\mathrm{t}_{\mathrm{s}}$ & $1.965 \mathrm{~s}$ & $2.04 \mathrm{~s}$ & $2.065 \mathrm{~s}$ \\
\hline $\mathrm{t}_{\mathrm{r}}$ & $1.155 \mathrm{~s}$ & $1.199 \mathrm{~s}$ & $1.214 \mathrm{~s}$ \\
\hline $\mathrm{t}_{\mathrm{d}}$ & $0.974 \mathrm{~s}$ & $1.011 \mathrm{~s}$ & $1.024 \mathrm{~s}$ \\
\hline $\mathrm{e}_{\mathrm{ss}}$ & 0 & 0 & 0 \\
\hline
\end{tabular}

Berdasarkan hasil respon dan hasil analisa respon untuk tiga posisi. Pengendali PID-Gain Scehdulling mampu menmbuat sistem menjejaki setpoint yang diberikan untuk tiga posisi berbeda. Gain-schedulling juga mampu mengoptimalkan kinerja PID, dan menjadwalkan parameter PID yang sesuai dengan tiga kondisi yang berbeda tersebut. Terbukti dengan error minimum, dan kontanta waktu yang kecil menunjukkan pencapaian setpoint dalam waktu yang cepat.

\section{Kesimpulan}

1. Perancangan pengendali PID dengan optimasi Gain Schedulling untuk mengendalikan tiga kondisi posisi magnetic levitation ball telah berhasil dan menunjukkan performasi yang baik. Hal ini terbukti dari hasil setpoint yang diberikan berhasil dicapai, dan gangguan yang diberikan juga berhasil diatasi.

2. Pengendali gain scheduling berhasil mengoptimalkan pengendali PID terbukti dengan perubahan setpoint posisi magnetic levitation ball mampu diikuti oleh sistem.

3. Pengendalian posisi magnetic levitation ball pada posisi $0.01 \mathrm{~m}$, $0.0125 \mathrm{~m}, \quad 0.015 \mathrm{~m}$ menggunakan 
pengendali PID gain scheduling menunjukkan performansi yang baik dibuktikan dengan kontanta waktu yang diperoleh adalah $\tau=0.393$ detik, $\quad \tau=0.408$ detik, $\quad \tau=0.413$ detik, dengan error minimum.

\section{Ucapan Terimakasih}

Penulis mengucapkan terimaskasih kepada mahasiswa : Rahmat Andi Kurniawan yang telah membantu melaksanakan penelitian ini

\section{Daftar Pustaka}

[1] Hypiusová. Mária. PID Controller Design For Magnetic Levitation Model. Slovak University of Technology.2010

[2] A.K.Mishra, R.Raina, dkk. "Modeling and Simulation of Levitating Ball by Electromagnet using Bond Graph", Indian Institute of Technology Patna, 2013

[3] C.Chen, Y.Sun. dkk. " Design of Magnetic Levitation Ball Control Based on Co-simulation of SIMULINK and ADAMS", College of Logistics Engineering, Shanghai Maritime University, China, 2016

[4] M.S.Abu. Nasr. "Fuzzy Gain Schedulling Control for Non-Linear System", The University of Gaza, Thesis Electrical Engineering, 2013

[5] D.B.Wibowo dan Sindu Sutomo. "Pemodelan dan Simulasi Sistem Control Magnetic Levitation Ball ", Universitas Diponegoro, 2011

[6] Setiawan, Iwan. Kontrol PID Untuk Proses Industri. ISBN: 978-979-274100-1, Elex Media Komputindo, 2008.

[7] Ogata, Katsuhiko, “Modern Control Engineering”, Prentice-Hall, New Delhi, 2002.

[8] Richard. Muhamad. Kontroler PID (PID Controller). Universitas Diponegoro. Semarang. 2013 